\title{
Desenvolvimento embrionário in vitro de embriões bovinos após a criopreservação pelo método one step, utilizando o etilenoglicol associado com a sacarose ${ }^{*}$
}

\author{
In vitro bovine embryo development after one step criopreservation, \\ using ethylene glycol plus sucrose
}

\author{
Éverson Fernandes Pinheiro, Eduardo Paulino da Costa," José Domingos Guimarães," Belmiro Zamperlini,"” \\ Ademir de Moraes Ferreira, "'” Wanderlei Ferreira de Sá"."
}

\section{Resumo}

Foram utilizadas oito novilhas mestiças Holandês $x$ Zebu como doadoras de embriões, no intuito de avaliar a capacidade de desenvolvimento embrionário após o procedimento de reidratação one step, utilizando o etilenoglicol associado à sacarose como crioprotetores. Os embriões, coletados entre o sexto e o sétimo dia após o estro, foram avaliados morfologicamente, distribuídos aleatoriamente em dois tratamentos. Os embriões foram cultivados in vitro em monocamada de células da tuba uterina. Após 48 horas de cultivo in vitro, os embriões foram avaliados quanto ao grau de desenvolvimento embrionário e número de células. Não foram observadas diferenças $(p>0,05)$ na taxa de desenvolvimento embrionário e no número de células entre os tratamentos. Estes resultados sugerem que a congelação e descongelação pelo método one step utilizando o etilenoglicol associado à sacarose, conforme procedimentos definidos no experimento, é um método viável, e que poderia ser utilizado na rotina de tecnologia de embriões.

Palavras-chave: Criopreservação "one step”; embriões; bovinos.

\section{Introdução}

A técnica de transferência de embriões em bovinos ganha, a cada dia, mais espaço dentro da pecuária nacional. Neste contexto, salienta-se o aspecto de que uma fêmea de elevado padrão zootécnico pode ser utilizada de forma mais racional, fornecendo grande número de descendentes em um curto espaço de tempo. Destarte, pode-se acelerar o processo de melhoramento genético em rebanhos bovinos.

A inovulação de embriões recém-coletados e não-congelados (embriões frescos) possibilita uma taxa de gestação aproximada de 62,5\% (Rumpf et al., 1992). Corroborando com estas afirmações, Zanenga (1993) obteve $71,8 \%$ e $58,7 \%$ de gestação, após a inovulação de embriões das subespécies Bos taurus taurus e Bos taurus indicos, respectivamente.

Os métodos convencionais para a transferência de embriões previamente congelados possibilitam uma taxa de gestação em torno de $45-55 \%$ (Rodrigues, 1992). Entretanto, esta metodologia requer várias etapas de manipulações individuais para a retirada do crioprotetor dos blastômeros (Franks et al., 1986 ; Suzuki et al., 1993), consome muito tempo e exige infra-estrutura especializada, o que representa um entrave para a disseminação da técnica (Agarwal et al., 1991 ; Molina e Saturnino, 1993). Adicionalmente, este procedimento apresenta um aumento de espera in vitro dos embriões descongelados, quando um grande número destes são descongelados e transferidos em um mesmo dia. Por outro lado, quando um pequeno número de embriões é transferido, temos um desperdício de tempo gasto com a preparação dos equipamentos e de materiais (Voelkel e Hu, 1992a).

As evoluções da técnica de congelação-descongelação de embriões estão relacionadas com a escolha do crioprotetor, a duração da fase de refrigeração, o recipiente de congelamento e as modalidades de diluição do crioprotetor (Massip et al., 1987).

\footnotetext{
"Trabalho extraído da monografia apresentada pelo primeiro autor, ao Departamento de Veterinária da Universidade Federal de Viçosa (UFV), para a obtenção do título de Especialista em Medicina Veterinária.

** Departamento de Veterinária, Universidade Federal de Viçosa - 36571-000 - Viçosa, MG, Brasil.

"** Departamento de Zootecnia, Universidade Federal de Viçosa.

*.** Empresa Brasileira de Pesquisa Brasileira - Centro Nacional de Pesquisa de Gado de Leite.
} 
Desde a última década tem sido tentado um procedimento simplificado, utilizando a adição e remoção de crioprotetores em etapa única, denominada one step. Nenhuma sofisticação laboratorial é necessária, uma vez que os embriões não são manipulados fora da palheta (Voelkel e Hu 1992a). Entretanto, segundo Schneider e Mazur (1984), um dos grandes problemas da transferência direta é a baixa permeabilidade dos embriões aos crioprotetores convencionais. Assim, os dados da literatura sobre a taxa de desenvolvimento dos embriões apresentam grandes variações após a utilização do método one step, em função do procedimento, dos tipos e concentração dos crioprotetores utilizados (Renard et al., 1982 ; Voelkel e Hu, 1992a ; Massip, 1994).

A inclusão da sacarose associada a outros crioprotetores possibilitou o uso da reidratação direta, permitindo a inovulação dos embriões para as receptoras sem etapas intermediárias de reidratação (Hochi et al., 1996 ; Voelkel e Hu, 1992b). Assim, várias pesquisas têm sido realizadas com o método one step, utilizando como crioprotetor o glicerol associado com a sacarose. Deste modo, Leibo (1984) obteve 26\% de gestação, após 1259 inovulações. Melhores resultados (50\% de gestação) foram obtidos por Renard et al. (1982) e Massip et al. (1987), utilizando $1,36 \mathrm{~mol} \mathrm{~L}^{-1}$ de glicerol e $0,25 \mathrm{~mol} \mathrm{~L}^{-1}$ de sacarose e realizando uma pré-agitação antes da transferência direta.

Utilizando o propilenoglicol como crioprotetor em procedimento one step, Suzuki et al. (1990) obtiveram $61 \%$ de gestação após a inovulação de dois embriões para cada receptora.

Muitas pesquisas têm sido realizadas com o método one step, comparando o etilenoglicol com outros crioprotetores. Na transferência direta, o primeiro passo é determinar qual o crioprotetor que é mais permeável ao embrião. Assim, Széll et al. (1989), Massip (1994) citam que as mórulas compactas e os blastocistos bovinos são mais permeáveis ao etilenoglicol, quando comparados com os crioprotetores convencionais como o glicerol, o dimetilsulfóxido e o propilenoglicol. Esta maior permeabilidade ocorre pelo menor peso molecular do etilenoglicol, o que permite, conseqüentemente, uma remoção mais rápida deste do interior dos blastômeros, diminuindo assim, as chances de toxicidade e choque osmótico (Voelkel e Hu, 1992a, Massip, 1994). Esta condição possibilita que o etilenoglicol seja superior como crioprotetor (Cocero et al., 1988).

Diante disto, Voelkel e Hu (1992a) observaram melhores taxas de sobrevivência in vitro de embriões congelados com $1,5 \mathrm{~mol} \mathrm{~L}^{-1}$ de etilenoglicol (54\%), em relação aos congelados com 1,5 mol L-1 de propilenoglicol (20\%). Estes pesquisadores observaram ainda, após o teste de várias concentrações de etilenoglicol, que um melhor resultado pode ser encontrado com a concentração de 1,5 $\mathrm{mol} \mathrm{L}-1$ (62\% de desenvolvimento embrionário in vitroe 50 $\%$ de gestação após a inovulação). Também Voelkel e Hu (1992b) testando vários crioprotetores, observaram uma taxa de desenvolvimento embrionário in vitro de $75,16,35$, e $30 \%$, após o uso de $1,5 \mathrm{~mol} \mathrm{~L}^{-1}$ de etilenoglicol, propilenoglicol, dimetilsulfóxido e glicerol, respectivamente.

Este estudo teve como objetivo avaliar a influência do procedimento de criopreservação one step no desenvolvimento embrionário, utilizando o etilenoglicol associado a sacarose.

\section{Material e métodos}

O presente experimento foi desenvolvido nas dependências do Laboratório de Reprodução Animal do Departamento de Veterinária, após colheita de embriões de novilhas do Setor de Bovinocultura do Departamento de Zootecnia da Universidade Federal de Viçosa.

Seleção, avaliação e superovulação das doadoras: Foram utilizadas oito novilhas mestiças Holandês $x$ Zebu, em boa condição corporal e ciclando regularmente, sem nenhuma alteração anatômica ou inflamatória detectável através de palpação tranșretal e vaginoscopia. Estes animais foram selecionados após exames ginecológicos através de palpação transretal e vaginoscopia, para confirmar a inexistência de alterações anatômicas ou inflamatórias que poderiam excluir o animal do experimento.

O tratamento superovulatório teve início no dia 10 do ciclo estral (dia do estro = dia zero) com duas aplicações diárias intervaladas por 12 horas, via intramuscular, totalizando oito aplicações com um total de $750 \mathrm{UI}$ de FSH. ${ }^{1}$

Juntamente com a sétima dose do hormônio aplicou-se $0,5 \mathrm{mg}$ de cloprostenol, ${ }^{2}$ visando a lise do corpo lúteo formado após o último estro. Durante o estro induzido foram realizadas três inseminações, sendo a primeira efetuada imediatamente após o início da manifestação do estro e as outras duas intercaladas por 12 horas.

Colheita, manipulação e avaliação dos embriões: Os embriões foram coletados pelo método não-cirúrgico, entre 0 sexto e o sétimo dia após o estro, após anestesia epidural baixa com lidocaína. ${ }^{3}$ A lavagem dos cornos uterinos foi realizada através de catéter de foley número 18 ou 20 , utilizando solução de PBS de Dulbecco e Vogt, modificada por Wittinghan (1971) (DMPBS) e suplementada com $1 \%$ de soro inativado de vaca.

\footnotetext{
${ }^{1}$ Pluset - 500 UI de FSH por frasco- Laboratório Serono Produtos Farmacêuticos Ltda.

2 Ciosin - Ampola de $0,5 \mathrm{mg}$ de Cloprostenol - Laboratório Mallinckrodt Veterinária Ltda - Produtos \& Serviços Coopers.

${ }^{3}$ Anestésico Local S.P.V. - Laboratório Schering-Plough Veterinária.
} 
O líquido recuperado das lavagens uterinas foi filtrado em recipiente com malha de 80 micrômetros, onde os embriões ficavam retidos. No laboratório, o conteúdo do filtro foi transferido para uma placa de Petri com $15 \mathrm{~cm}$ de diâmetro e com o fundo quadriculado. Os embriões foram então localizados com o auxilio de um microscópio estereoscópio, manipulados e lavados em solução DMPBS suplementada com $10 \%$ de soro inativado de vaca.

Após a lavagem, os embriões foram classificados quanto ao estádio de desenvolvimento segundo Lindner e Wrigth (1983) e quanto ao aspecto morfológico conforme Kennedy et al. (1983).

Desidratação, congelação e descongelação dos embriões: Somente os embriões coletados e classificados quanto ao aspecto morfológico como I e II foram utilizados para o procedimento experimental. Estes embriões foram divididos aleatoriamente em dois tratamentos, logo após a avaliação das colheitas realizadas no dia. Foram utilizados 21 e 22 embriões para os tratamentos I e II, respectivamente.

Tratamento I: Para a desidratação, os embriões foram inicialmente imersos por cinco minutos em uma solução DMPBS, acrescida de $0,4 \%$ de BSA (albumina sérica bovina, fração $\mathrm{V}$ ) e $5 \%$ de glicerol. Posteriormente, estes embriões foram transferidos para uma solução de DMPBS, conforme descrição anterior, porém, acrescida de $10 \%$ de glicerol. Após 10 minutos de manutenção neste meio, os embriões foram envasados em palhetas médias e imersos em metanol contido em congelador biológico ${ }^{4}$ estabilizado em $-7^{\circ} \mathrm{C}$. A congelação e descongelação foi realizada seguindo procedimentos clássicos (Bem, 1989 ; Rodrigues, 1992).

A descongelação foi realizada no ar atmosférico, secando gentilmente a palheta com lenço de papel, evitando a formação de cristais de gelo. Após a descongelação, os embriões foram submetidos à reidratação em quatro etapas (Bem, 1989).

Tratamento II: Os embriões foram imersos e mantidos por 20 minutos em uma solução de DMPBS, acrescida de $0,4 \%$ de BSA (albumina sérica bovina, fração v) e $1,5 \mathrm{~mol}$ $\mathrm{L}^{-1}$ de etilenoglicol (Solução 1). Posteriormente, foram transferidos para um segundo meio conforme a solução 1, porém acrescida de $0,2 \mathrm{~mol} \mathrm{~L}^{-1}$ de sacarose e imediatamente após, os embriões foram envasados em palhetas médias e submetidos a congelação, em congelador biológico, conforme o Tratamento I. Para a descongelação, seguiuse a mesma técnica descrita para o Tratamento I, sem contudo submeter posteriormente os embriões a etapas de reidratação.
Cultivo dos embriões e avaliação do desenvolvimento embrionário: Os embriões foram co-cultivados em monocamada de células da tuba uterina durante 48 horas, em Meio de TCM enriquecido (Costa, 1994). Os cultivos foram realizados nas placas de Petri de 35 milímetros de diâmetro, contendo $4 \mathrm{ml}$ de TCM previamente equilibrado durante 1 hora a $39^{\circ} \mathrm{C}$, em atmosfera de $5 \%$ de $\mathrm{CO}_{2}, 95 \%$ de ar atmosférico e $95 \%$ de umidade.

A taxa de desenvolvimento embrionário foi avaliada após 48 horas de cultivo in vitro. Foram considerados viáveis os embriões que evoluíram quanto ao seu estágio de desenvolvimento, segundo Lindner e Wrigth (1983). O número de células dos embriões foi determinado também 48 horas após o cultivo, analisando os embriões viáveis através da técnica de Fukui e Ono (1989).

Análise estatística: Os dados obtidos de cada tratamento foram analisados pelo teste do qui quadrado para a taxa de clivagem (desenvolvimento embrionário). Para avaliar o número de células dos embriões após o cultivo in vitro, foi realizada a análise de variância (Gomes, 1977), utilizando o teste $F$.

\section{Resultados e discussão}

O número de embriões viáveis após a descongelação e cultivo in vitro para os tratamentos I e II encontram-se sumarizados na Tabela 1. Não houve diferença $(p>$ $0,05)$ entre os dois tratamentos. Também Voelkel e Hu (1992b) não encontraram diferença significativa no número de embriões viáveis, comparando o uso de $1,5 \mathrm{~mol}$ $\mathrm{L}^{-1}$ de etilenoglicol em procedimento one step com o método convencional, utilizando o glicerol como crioprotetor (92 vs $73 \%$ de desenvolvimento embrionário, respectivamente). Estes resultados sugerem que o método de descongelação one step, da forma como foi realizado, poderá ser utilizado em substituição ao convencional, devido a sua simplicidade e facilidade de aplicação prática.

O procedimento convencional (Tratamento I) possibilitou $66,7 \%$ de desenvolvimento embrionário após 48 horas de cultivo in vitro. Este percentual observado foi semelhante aos encontrados por outros pesquisadores, indicando que esta técnica, apesar de laboriosa, pode apresentar resultados satisfatórios. Corroborando com estes resultados, Voelkel e Hu (1992b) obtiveram $73 \%$ de desenvolvimento embrionário in vitro. Resultados similares também foram obtidos após a inovulação dos embriões, por Voelkel e Hu, $1992 b$; Zanenga, 1993 ; Hasler et al., 1995.

\footnotetext{
${ }^{4}$ FTS Systems - BC - $40-1 \mathrm{~A}$, com curva de resfriamento programável até - $40^{\circ} \mathrm{C}$.
} 
Tabela 1: Viabilidade de embriões bovinos criopreser vados através do procedimento convencional $(\mathrm{Tl}) \mathrm{e}$ pelo método one step, utilizando como crioprotetor o etilenoglicol associado à sacarose (T II), após a descongelação e cultivo in vitro por 48 horas.

\begin{tabular}{clc}
\hline Tratamento & $\mathrm{N} 1$ & $\mathrm{~N} 2$ \\
\hline T I & 21 & $14(66,7)^{\mathrm{a}}$ \\
T II & 22 & $13(59,1)^{\mathrm{a}}$ \\
\hline
\end{tabular}

$\mathrm{N} 1=$ Número de embriões congelados

$\mathrm{N} 2=$ Número de embriões viáveis pós-cultivo (\%)

Letras iguais na mesma coluna, não apresentam diferenças $(p>0,05)$

pelo método do qui-quadrado.

A inovulação de embriões recém-coletados e não-congelados (embriões frescos) tem apresentado uma taxa de gestação aproximada de 62,5\% (Rumpf et al., 1992), $65,5 \%$ (Molina e Saturnino, 1993), 71,8\% e 58,7\% (Zanenga, 1993). Entretanto, o procedimento convencional de congelação possibilita taxas de desenvolvimento in vitro pós-descongelação ou de gestação após inovulação similares às obtidas na rotina de transferência de embriões frescos. Destarte, justifica-se o uso deste procedimento convencional como controle em pesquisas de alternativas de criopreservação, tal como foi realizado neste experimento.

O procedimento de congelação e descongelação pelo método one step (Tratamento II) possibilitou uma taxa de $59,1 \%$ de desenvolvimento embrionário após 48 horas de cultivo in vitro. Resultados semelhantes (54\%) foram encontrados por Voelkel e Hu (1992a). Também Suzuki et al. (1993), utilizando embriões produzidos in vitro, obtiveram $50 \%$ de desenvol-vimento embrionário in vitro com a reidratação direta. Estes resultados encontrados no presente experimento também foram semelhantes à taxa de gestação (52\%) obtida por Dochi et al. (1995), utilizando $1,8 \mathrm{~mol} \mathrm{~L}^{-1}$ de etilenoglicol, associado com sacarose.

Resultados ligeiramente superiores aos encontrados neste experimento foram relatados por Voelkel e $\mathrm{Hu}$ (1992b), os quais obtiveram $75 \%$ de desenvolvimento embrionário, após 48 horas de cultivo in vitro. Resultados superiores também foram obtidos após a inovulação por Suzuki et al. (1993) e Dochi et al. (1995), onde os autores obtiveram uma taxa de gestação de $74 \%$ e $69 \%$, respectivamente. Entretanto, todos estes pesquisadores citados utilizaram somente o etilenoglicol como crioprotetor nos procedimentos de criopreservação. É provável que estes resultados obtidos, ligeiramente superiores ao verificado no presente experimento, tenham sido por esta razão. Deste modo, a grande permeabilidade dos embriões ao etilenoglicol (Massip, 1994) possibilitaria um certo equilíbrio entre a saída deste crioprotetor e a entrada de água, durante a reidratação, evitando, então, a presença de sacarose no meio, a qual pode exercer efeitos tóxicos nas células (Suzuki, et al., 1993; Dochi et al., 1995).

Resultados variáveis foram obtidos através do procedimento one step, utilizando outros crioprotetores ao invés do etilenoglicol. Assim, utilizando o glicerol associado à sacarose, Molina e Saturnino (1993) não verificaram nenhuma gestação após a inovulação em receptoras, enquanto Dochi et al. (1995) obtiveram 60\% de animais gestantes. Utilizando estes mesmos crioprotetores, Voelkel e $\mathrm{Hu}(1992 \mathrm{~b})$ observaram somente $30 \%$ de sobrevivência embrionária após cultivo in vitro. Da mesma forma, o uso do propilenoglicol possibilitou $58 \%$ de desenvolvimento embrionário in vitro (Suzuki et al., 1993), enquanto outros trabalhos relatam somente $20 \%$ de sobrevivência (Voelkel e Hu, 1992a) ou 16\% (Voelkel e Hu, 1992b). Outros crioprotetores também foram utilizados em criopreservação, como a metilcelulose, o dietilenoglicol, os quais possibilitaram $53,6 \%$ e $56,9 \%$ de desenvolvimento embrionário in vitro, respec-tivamente (Suzuki et al., 1993) e o dimetilsulfóxido, com o qual foi obtida uma taxa de 35\% de sobrevivência (Voelkel e Hu, 1992b).

O uso do etilenoglicol na reidratação direta apresenta maiores perspectivas em relação aos crioprotetores convencionais como o glicerol, o propilenoglicol e o dimetilsulfóxido, por ser mais permeável à membrana citoplasmática dos embriões (Cocero et al., 1988 ; Szell et al., 1989). Em razão desta maior permeabilidade, os embriões expostos ao etilenoglicol retornam mais cedo ao seu volume original (10 minutos), quando comparados com a exposição por exemplo ao glicerol (30 minutos), diminuindo assim o tempo de injurias produzidas pelo crioprotetor (Voelkel e Hu, 1992a). É provável que esta propriedade do etilenoglicol seja o principal fator responsável pelos resultados mais consistentes e geralmente mais satisfatórios quando comparado com o uso de outros crioprotetores em procedimentos one step.

O número médio de células encontradas em embriões cultivados in vitro (Tabela 2) foi 98,2 no grupo congelado pelo procedimento convencional, utilizando o glicerol (Tratamento I) e 74,3 no grupo congelado pelo procedimento one step, utilizando o etilenoglicol associado à sacarose (Tratamento II). Estas diferenças entre os tratamentos não foram significativas $(p>0,05)$, indicando que o índice de multiplicação celular pode não ser prejudicado após o procedimento de reidratação direta (one step), quando se utiliza o etilenoglicol associado a sacarose. 
Tabela 2: Número médio de células encontradas em embriões criopreservados através do procedimento convencional (T I) e pelo método one step, utilizando como crioprotetor o etilenoglicol associado à sacarose (T II), após a descongelação e cultivo in vitro por 48 horas.

\begin{tabular}{ccc}
\hline Tratamento & Média & Desvio padrão \\
\hline TI & 98,2 & $16,9^{\mathrm{a}}$ \\
T II & 74,3 & $29,3^{\mathrm{a}}$ \\
\hline
\end{tabular}

Letras iguais na mesma coluna não apresentam diferenças $(p>0,05)$, pelo teste $\mathrm{F}$.

Este número médio de células observado para os dois tratamentos foi inferior ao verificado por Picard et al. (1986) utilizando embriões produzidos in vivo, porém, sem prévia congelação, os quais observaram uma média de 160 células para blastocisto expandido. Os resultados obtidos no experimento também foram inferiores aos verificados em pesquisas com embriões produzidos in vitro. Deste modo, foram inferiores à média obtida de 122,2 células em embriões cultivados até o oitavo dia pós-inseminação (Farin et al., 1995) e também a variação de 100 a 150 células de embriões inseminados in vitro e cultivados por 7 dias (Fukui e Ono, 1989). O menor número de células encontrado neste trabalho, quando comparado com os obtidos por estes pesquisadores, poderia ter ocorrido pelo fato dos embriões terem sido congelados, o que não aconteceu nos trabalhos realizados por estes autores, os quais utilizaram embriões não congelados, uma vez que a criopreservação pode ser extremamente destrutiva para a organização celular do zigoto (Dobrinsky, 1996). Também Aller et al. (1995) citam que embriões congelados e descongelados terão menos blastômeros viáveis devido aos efeitos da congelação (desidratação, formação de cristais, aumento da concentração de solutos e reidratação).

\section{Abstract}

The objetive of this study was to evaluate the use of ethylene glycol plus sucrose on one-step thawed method. Twenty one embryos at the morula stage collected on day 6 (estrus designated day 0 ) were frozen and thawed by conventional methods, in medium containing glycerol $(10 \%)$ as the cryoprotectant (control embryos, treatments). The qui square analysis on survival rates and the variance analysis of number of cell were not significantly different $(p>0.05)$ between treatments. These experiments demonstrate that $1.5 \mathrm{~mol} \mathrm{~L}^{-1}$ ethylene glycol plus $0.2 \mathrm{~mol} \mathrm{~L}^{-1}$ sucrose was cryoprotectant effective for the one-step thawed method. Nevertheless, emphasize that there is a necessity of new research about the use of ethylene glycol associate or not to the other cryoprotectant allowing a major efficiency in the results.

Keywords: Bovine, embryos, one-step criopreservation, ethylene glycol plus sucrose.

\section{Referências bibliográficas}

AGARWAL, S. K. et al. Cryopreservation of cattle embryos. Indian Journal of Animal Sciences, v. 61, no. 11, p. 1195-1196, 1991.

ALLER, J. F. et al. Criopreservación de embriones mamiferos $1^{\mathrm{a}}$. Parte. Características generales de la congelación. $R$. de Med. Vet., v. 76, n. 2, p. $132-136,1995$.

BEM, A. R. National position paper: embryo transfer technology for genetic improvement. In: GLOBAL WORKSHOP FOR BIOTECNOLOGY APPLIED TO ANIMAL PRODUCTION \& HEALTH, 9-13, 1989, Beijing, China.

COCERO, M. J. et al. Glycerol or ethyleno glycol for cryoprotection of deep frozen ewe embryos. Theriogenology, v. 29, no.1, p. 238, 1988.

COSTA, E. P. Aspectos morfológicos (citológicos e ultra-estruturais) e desenvolvimento de ovócitos de bovinos in vitro. 1994. $155 \mathrm{f}$. Tese (Doutorado). Escola de Veterinária, Universidade Federal de Minas Gerais, 1994.

DOBRINSKY, J. R. Cellular approach to cryopreservation of embryos. Theriogenology, v. 45, p. 17 - 26, 1996.

DOCHI, O., IMAI, K., TAKAKURA, H. Birth of calves after direct transfer of thawed bovine embryos stored frozen in ethylene glycol. Animal Reproduction science, v. 38, p. 179-185, 1995.
FARIN, C. E., HASLER, J. F., MARTUS, N. S. Comparison of Menezo B2 and TCM - 199 Media for in vitro production of bovine blastocysts. Theriogenology, v. 43, no. 1, p. 210, 1995.

FRANKS, G. C. ; COLEY, S. L., BETTERBED, B., PAGE, R. D. The effect of freezer type cryoprotectant, and processing methods on viability of frozen embryos. Theriogenology, v. 26, no. 2, p. 135-144, 1986.

FUKUI, Y. \& ONO, H. Effects of sera, hormones and granulosa cells added to culture medium for in vitro maturation, fertilization, cleavage and development of bovine oocytes. J. Reprod. Fertil., v. 86, p. 501-506, 1989.

GOMES, F. P. Curso de estatística experimental. 7. ed. Piracicaba: Nobel, 1977. $430 \mathrm{p}$.

HASLER, J. F., HENDERSON, W. B., HURTGEN, P. J. et al. Production, freezing and transfer of bovine IFV embryos and subsequent calving results. Theriogenology, v. 43, p. 141-152, 1995.

HOCHI, S., MARUYAMA, K., OGURI, N. Direct transfer of equine blastocysts frozen-thawed in the presence of ethylene glycol and sucrose. Theriogenology, v. 46, p. 1217-1224, 1996.

KENNEDY, L. G., BOLAND, M. P., GORDON, I. The effect of embryo quality at freezing on subsequent developement of thawed cow embryos. Theriogenology, v. 19, no. 6, p. 823832, 1983. 
LINDNER, G. M., WRIGHT, Jr. R. W. Bovine embryo morphology and avaluation. Theriogenology., v. 20, p. 407-416, 1983.

MASSIP, A., VAN DER ZWALMEN, P., ECTORS, F. Recent progress in criopreservation of cattle embryos. Theriogenology, v. 27, n. 1, p. 69, 1987.

MASSIP, A. Aspectos técnicos de los métodos rápidos de congelación de los embriones de mamíferos (vaca). Med. Vet., v. 11, n. 7-8, p. 388-394, 1994.

MOLINA, L. R., SATURNINO, H. M. Avaliação do método one step na criopreservação de embriões bovinos da raça nelore. $R$. bras. Reprod. Anim., v. 17, p. 89-96, 1993.

PICARD, L., GREVE, T., KING, W, A., BETTERIDGE, K. J., HOLM JORGENSEN, P. Bisection of post - compaction bovine embryos: The difference in viability between the monozygotic halves. Acta vet. Scand., no. 27, p. 33- 48, 1986.

RENARD, J, P. , HEYMAN, Y., OZIL, J. P. Congélation de l'embryon bovin: une nouvelle méthode de décongélation pour le transfert cervical d'embryons condetionnés une seule fois en paillet. Ann. Méd. Vét., v.126, p. 23-32, 1982.

RODRIGUES, J. L. Aspectos da congelação de embriões bovinos. In: REUNIÃO ANUAL DA SOCIEDADE BRASILEIRA DE TRANSFERÊNCIA DE EMBRIÕES, 7., Jaboticabal, 1992. Anais... Jaboticabal, 1992. p. 55-79

RUMPF, R., BEM, A. R., SOUZA, R. V., PEIXER, M. A. S. Bissecção de embriões de bovinos. In: REUNIÃO ANUAL DA SOCIEDADE BRASILEIRA DE TRANSFERÊNCIA DE EMBRIÕES, 7., Jaboticabal, 1992. Anais... Jaboticabal, 1992. p. 92.
SCHINEIDER, U., MAZUR, P. Osmotic consequences of cryoprotectant permeability and its relation to the survival of frozen-thawed embryos. Theriogenology, v. 21, n. 1, p. 68-78, 1984.

SUZUKI, T., YAMAMOTO, M., OOE, M. et al. Effect of sucrose concentration used for one-step diluition upon in vitro survival of bovine embryo refrigerated in glycerol and 1 , 2-propanediol. Theriogenology, v. 34, p. 1051-1057, 1990.

, TAKAGI, M., YAMAMOTO, M. et al. Pregnancy rate and survival in culture of in vitro fertilized bovine embryos frozen in various cryoprotectants and thawed using a one-step system. Theriogenology, v. 40, p. 651-659, 1993.

SZÉLL, A., SHELTON, J. N., SZÉLL, K. Osmotic characteristics of sheep and cattle embryos. Cryobiology, v. 26, p. 297-301, 1989.

VOELKEL, S. A., HU, Y. X. Direct transfer of frozen-thawed bovine embryos. Theriogenology, v. 37, p. 23-36, 1992a.

. Use of ethylene glycol as a cryoprotectant for bovine embryos allowing direct transfer of frozen-thawed embryos to recipient females. Theriogenology, v. 37, p. 687-697, 1992b.

WHITTINGHAM, D. G. Survival of mouse embryos after freezing and thawing. Nature, v. 233, p. 125, 1971.

ZANENGA, C. A. Congelação de embriões em zebuínos, evolução e viabilidade. In: CONGRESSO BRASILEIRO DE REPRODUÇÃO ANIMAL, 10., Belo Horizonte, 1993. Anais...Belo Horizonte, 1993. p. 125.

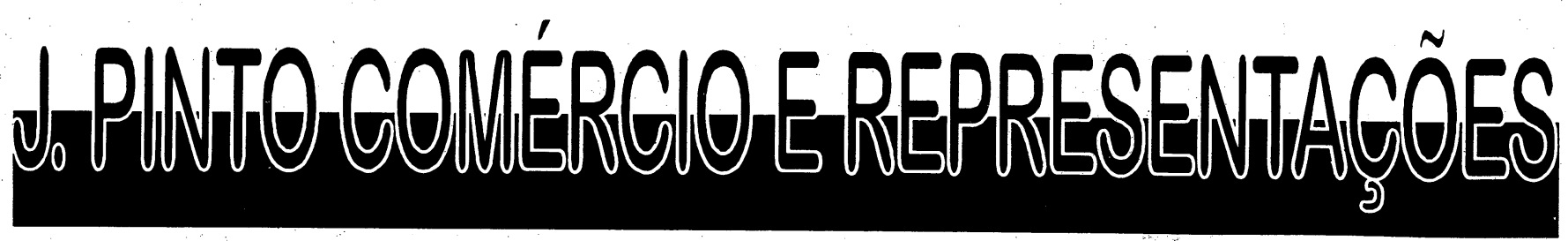

J. Pinto de Macedo - Livraria

- Especializada em Livros Técnicos Científicos (Nacionais e Estrangeıros

- Equipamentos Médicos

- Materiais Cirúrgicos em Geral

- Laboratorial.

- Medicamentos Veterinários

\author{
Rua Vital Brazil Filho, 64 - Parte \\ (FACULDADE DE VETERINÁRIA) \\ Niterói - RJ - Caixa Postal 126-048 CEP 24241-970 - Tel.: (021) 7110-0229
}

